\title{
Pólen apícola como aditivo em dietas para frangos de corte
}

\author{
Rômulo Batista RODRIGUES ${ }^{1 *}$, Luiz Eduardo Avelar PUCCI ${ }^{2}$, Juliano UCZAY², \\ Mabel MOLINARI ${ }^{2}$, Rafael LAZZARI², Mariana UCZAY ${ }^{3}$
}

\begin{abstract}
${ }^{1}$ Programa de Pós-Graduação em Zootecnia, Universidade Federal do Rio Grande do Sul, Porto Alegre, RS, Brasil. ${ }^{2}$ Departamento de Zootecnia e Ciências Biológicas, Universidade Federal de Santa Maria, Palmeira das Missões, RS, Brasil. ${ }^{3}$ Programa de Pós-Graduação em Bioquímica e Biologia Molecular, Universidade do Estado de Santa Catarina, Lages, SC, Brasil. *E-mail: rrodrigues1903@gmail.com
\end{abstract}

Recebido em novembro/2017; Aceito em março/2018.

RESUMO: O pólen apícola é um produto natural constituído por vários nutrientes, rico em aminoácidos livres e com baixo teor de gordura, além de propriedades profiláticas e terapêuticas, desta maneira é uma excelente opção na nutrição animal e pode oferecer benefícios ao desempenho e saúde dos animais de produção. Este trabalho foi realizado para avaliar o uso de pólen apícola em dietas para frangos de corte. Foram utilizados 105 pintos machos com um dia de idade, linhagem Cobb $500^{\circledR}$ (peso inicial $=38,95 \pm 2,37 \mathrm{~g}$ ), em delineamento inteiramente casualizado e alimentados durante 42 dias. Foram utilizados três tratamentos, com diferentes níveis de inclusão de pólen apícola $(0,15.000,30.000 \mathrm{mg} / \mathrm{kg})$ e cinco repetições. Foram avaliadas as seguintes variáveis: desempenho zootécnico (consumo de ração, ganho de peso, conversão alimentar, viabilidade e índice de eficiência produtiva), características de carcaças (rendimento de carcaça, peito, coxa e sobrecoxa, asas, fígado, moela e coração) e histomorfometria intestinal (profundidade de cripta, largura da vilosidade e altura da vilosidade). Observou-se diferença entre os tratamentos sobre os parâmetros de ganho de peso, consumo de ração, conversão alimentar, índice de eficiência produtiva, rendimento de coxa e sobre coxa, de fígado, de coração e moela dos frangos de corte. $\mathrm{Na}$ análise de histomorfometria intestinal, a altura da vilosidade foi diferente entre os tratamentos. Recomenda-se a utilização de $30.000 \mathrm{mg} / \mathrm{kg}$ de pólen apícola na dieta por melhorar o desempenho dos frangos de corte.

Palavras-chave: aves, desempenho zootécnico, nutrição, suplementação.

\section{Pollen as additives in diets for broilers}

\begin{abstract}
The bee pollen is a natural product consisting of several nutrients, rich in free amino acids and low in fat, and prophylactic and therapeutic properties, so it is an excellent choice in animal nutrition and can offer benefits to the performance and health of animals of production. This study was conducted to evaluate the use of pollen in diets for broilers. We used 105 broiler chicks of one day old Cobb 500 (initial weight $=38.95 \pm$ $2.37 \mathrm{~g}$ ) in a completely randomized design and fed for 42 days. Three treatments were used, with different inclusion levels of pollen $(0,15000$ and $30000 \mathrm{mg} / \mathrm{kg})$ and five replications. We evaluated the following variables: performance (feed intake, weight gain, feed conversion, feasibility and Productive Efficiency Ratio), carcass traits (carcass yield, breast, leg and thigh, wings, liver, gizzard and heart) and rates of intestinal morphometry (crypt depth, villus width and villus height). It was observed a difference between treatments on the parameters of weight gain, feed intake, feed conversion, productive efficiency index, yield and thigh on thigh, liver, heart and gizzard of broilers. In morphometric analysis intestinal villus height was between treatments. It is recommended to use $30,000 \mathrm{mg} / \mathrm{kg}$ of pollen in the diet to improve the performance of broilers.
\end{abstract}

Keywords: chicken, growth performance, nutrition, supplementation.

\section{INTRODUÇÃO}

$\mathrm{O}$ crescimento na produção de frangos tem feito com que pesquisas sejam realizadas visando soluções a fim de atender as necessidades nutricionais das aves que, devido ao rápido crescimento, passaram a exigir alimentos de melhor qualidade (OPALINSKIL et al., 2010), além disso, atualmente as pesquisas estão direcionando seus esforços na busca de novos alimentos que possam ser utilizados nas dietas dos animais de produção que possam oferecer benefícios ao desempenho e saúde dos animais, aumentando assim as opções de alimentos que podem ser incluídos nas dietas pelas indústrias.

Doses subterapêuticas de antibióticos como aditivos nas dietas das aves foram utilizadas por décadas visando á melhoria no desempenho dos animais pelo efeito promotor de crescimento oferecido, no entanto, surgiram preocupações com o uso de antibióticos, devido ao risco desses produtos deixarem resíduos nos animais, que podem ser tóxicos e ainda promover o aparecimento de bactérias resistentes (PELICANO et al., 2005). O que tem feito com que ocorra uma crescente preocupação dos consumidores com a origem e qualidade dos produtos, exigindo alimentos saudáveis e sem resíduos (ZAVARIZE et al., 2011), além disso, diversos países proibiram o uso de antibióticos como promotores de crescimento para frangos devido aos problemas com resistência bacteriana cruzada e risco de deixar resíduos na carne, como a União Européia por exemplo que proibiu o uso desde 2006. Com isso, estudos sobre produtos alternativos aos antibióticos que podem oferecer melhorias no desempenho, no aproveitamento dos nutrientes das dietas e na manutenção da saúde intestinal, sem deixar resíduos nocivos estão sendo 
realizados (ZHANG et al., 2005). Nesse contexto os produtos apícolas vêm despertando o interesse por suas características nutricionais e funcionais, pois além da composição química básica, esses produtos possuem substâncias benéficas à saúde (CARPES et al., 2009).

O pólen apícola é um aglomerado de pólen das flores recolhidos a partir de várias fontes de plantas pelas abelhas e misturado com néctar e secreções das glândulas da hipofaringe (CARPES et al., 2008). Apresenta como principais componentes os carboidratos (13 a 55\%), fibra bruta $(0,3$ a 20\%), proteínas (10 a 40\%) e lipídeos (1 a 10\%) (HAŠČÍK et al., 2015). No entanto, a composição do pólen apícola depende de fatores ambientais, como a origem vegetal, condições climáticas, tipo de solo e o trabalho do apicultor (MORAIS et al., 2011).

O pólen é a principal fonte de proteína na nutrição de abelhas, pode ser encontrado em sua composição aminoácidos essenciais como: lisina, triptofano, histidina, leucina, isoleucina, valina, entre outros, além de vitaminas A, C, D, K3 e do complexo B (DIAS et al., 2013). Os carboidratos são principalmente compostos de polissacarídeos insolúveis, além de amido, frutose, glucose e sacarose, e a gordura presente no pólen é composta de diferentes lipídeos, ácidos graxos, esteróis e os hidrocarbonetos (BOGDANOV, 2004). Há ainda a presença de compostos secundários como minerais, carotenóides, compostos fenólicos, flavonóides e esteróis (FEÁS et al., 2012).

Além da composição química rica em diversos macro e micronutrientes, o pólen pode ser utilizado para fortalecer o sistema imunológico, para reduzir o efeito da radiação e retardar o envelhecimento em humanos, devido ao seu conteúdo de flavonóides e antioxidante (GEYMAN, 1994), ainda pode apresentar outros efeitos terapêuticos interessantes como: antimicrobiano, antifúngico, hepatoprotetor, quimiopreventivo e anti-inflamatório, que foi observado in vitro por PASCOAL et al. (2014).

Estudos demonstram que o pólen melhora os parâmetros de desempenho e saúde de animais de interesse zootécnico. Houve melhoras no crescimento de frangos (WANG et al., 2007), no desempenho reprodutivo de coelhos (ATTIA et al., 2010), no desempenho de tilápias (Oreochromis niloticus) (ABBASS et al., 2012), entre outros. Em parâmetros histomorfológicos de aves, trabalhos verificaram que o pólen aumenta o tamanho das vilosidades, otimizando assim a absorção de nutrientes (BELLONI et al., 2012; WANG et al., 2005; 2007)

Objetivou-se com este trabalho avaliar a utilização de pólen apícola em dietas para frangos de corte, avaliando seu efeito sobre o desempenho zootécnico, características de carcaça e histomorfometria intestinal.

\section{MATERIAL E MÉTODOS}

O experimento foi conduzido no Laboratório de Avicultura do Departamento de Zootecnia e Ciências Biológicas da Universidade Federal de Santa Maria (UFSM), campus de Palmeira das Missões-RS, Brasil. Foram utilizados 105 pintos machos, linhagem Cobb $500^{\circledR}$ com um dia de idade, e peso médio inicial de $38,95 \pm 2,37 \mathrm{~g}$, distribuídos em delineamento inteiramente casualizado (DIC), com três tratamentos, cinco repetições de sete aves cada, totalizando 15 unidades experimentais. As aves foram alojadas em gaiolas metálicas suspensas com dimensões de $80 \mathrm{~cm}$ x $60 \mathrm{~cm}$ x $45 \mathrm{~cm}$, equipadas com bebedouros e comedouros.

As dietas experimentais consistiram de ração comercial para frangos de corte de 1 a 21 dias (Inicial) e de 22 a 42 dias (Crescimento) (Tabela 1), com adição de níveis crescentes de pólen apícola $(0,15.000,30.000 \mathrm{mg} / \mathrm{kg})$. Determinou-se nas dietas (Tabela 2) as seguintes variáveis bromatológicas: matéria seca, cinzas, proteína bruta (AOAC, 2005) e teor de lipídeos (BLIGH; DYER, 1959).

Tabela 1. Análise bromatológica proximal da dieta comercial enriquecida com pólen apícola utilizada para a alimentação dos frangos de corte.

Table 1. Proximate analysis of the commercial diet supplemented with bee pollen utilized to feed broiler).

\begin{tabular}{lcc}
\hline \multicolumn{1}{c}{ Nutrientes (\%) } & Ração inicial $^{2}$ & $\begin{array}{c}\text { Ração de } \\
\text { crescimento }^{2}\end{array}$ \\
\hline Umidade (máx) & 12,5 & 12,5 \\
Proteína Bruta (mín) & 22,0 & 21,0 \\
Extrato Etéreo (mín) & 3,0 & 3,0 \\
Matéria Fibrosa (máx) & 8,0 & 7,0 \\
Matéria Mineral (máx) & 8,0 & 7,0 \\
Cálcio (máx) & 1,0 & 1,1 \\
Cálcio (mín) & 0,7 & 0,9 \\
Fósforo (mín) & 0,6 & 0,6 \\
Sódio (mín) & 0,2 & 0,2 \\
Lisina (mín) & 1,15 & 1,1 \\
Metionina (mín) & 0,6 & 0,33 \\
\hline
\end{tabular}

${ }^{1}$ Composição: Farelo de soja, farelo de trigo, milho integral moído, gordura vegetal, farinha de carne e ossos, calcário calcítico, cloreto de sódio, fosfato bicálcio, vitaminas $A, D_{3}, E, K_{3}, B_{1}, B_{2}, B_{6}, B_{12}$, niacina, pantotenato de cálcio, ácido de fólico, cloreto de colina, sulfato de ferro, sulfato de cobre, sulfato de manganês, sulfato de zinco, selenito de sódio, iodato de cálcio, aditivo antioxidante (BHT).

${ }^{2}$ Fonte: Agrobella Alimentos ${ }^{\circledR}$

Tabela 2. Composição bromatológica proximal das dietas experimentais analisada.

Table 2. Proximal composition of the experimental diets analyzed).

\begin{tabular}{lccc}
\hline \multicolumn{1}{c}{$\begin{array}{c}\text { Composição } \\
\text { proximal (\%) }\end{array}$} & \multicolumn{3}{c}{ Níveis de inclusão de pólen apícola $(\mathrm{mg} / \mathrm{kg}$ ) } \\
\cline { 2 - 4 } & 0 & 15.000 & 30.000 \\
\hline \multicolumn{4}{c}{ 1 a 21 dias (Ração inicial) } \\
\hline Matéria seca & 89,10 & 89,05 & 89,34 \\
Matéria mineral & 9,45 & 9,20 & 9,28 \\
Lipídeos & 5,95 & 6,02 & 6,10 \\
Proteína bruta & 22,60 & 22,74 & 22,85 \\
\hline \multicolumn{4}{c}{ 22 a 42 dias (Ração crescimento) } \\
\hline Matéria seca & 89,25 & 89,33 & 88,20 \\
Matéria mineral & 9,75 & 9,58 & 9,83 \\
Lipídeos & 6,26 & 6,37 & 6,34 \\
Proteína bruta & 21,22 & 21,77 & 21,99 \\
\hline
\end{tabular}

${ }^{1}$ Valores analisados.

As aves receberam água e ração à vontade durante todo o período experimental, sendo a quantidade de ração fornecida por unidade experimental aferida para realização da estimativa de consumo de ração e conversão alimentar. Foram aferidas diariamente a temperatura com o auxílio de um termo higrômetro digital, nos períodos da manhã e da tarde, visando o monitoramento e controle de temperatura indicada para o conforto dos animais em cada fase do desenvolvimento. O controle de temperatura quando necessário foi realizado com uso de lâmpadas e uso de cortinas para a manutenção de calor nas unidades experimentais, e o uso do levantamento da cortina e uso dos ventiladores quando necessário a diminuição da temperatura das unidades experimentais. $\mathrm{O}$ manejo foi 
realizado para manter a temperatura em uma faixa de conforto para frangos entre cerca de 22 e $27^{\circ} \mathrm{C}$ (FURTADO et al., 2003), sendo que o uso de lâmpadas e cortinas geralmente foi realizado nos períodos do entardecer ao amanhecer quando a temperatura é mais baixa, e o uso de ventiladores no período diurno quando há um aumento de temperatura, porém esses manejos sempre foram condicionados a temperatura aferida no momento, de acordo com a necessidade da idade dos animais O manejo sanitário foi realizado pela limpeza das gaiolas, comedouros, bebedouros e substituição das camas de maravalha a cada 15 dias.

Aos 21 dias de idade e ao final do período experimental foram realizadas pesagens das aves e sobras de rações, para avaliação do desempenho zootécnico (consumo de ração, ganho de peso e conversão alimentar), foram calculados também a viabilidade e o índice de eficiência produtiva. A determinação do consumo de ração $(\mathrm{CR})$ foi realizada pela diferença entre a quantidade inicial fornecida no experimento pelas sobras dos comedouros no último dia de cada fase de produção, em cada unidade experimental em relação ao número de aves corrigido pela mortalidade.

O ganho de peso (GP) foi determinado através da pesagem do grupo de frangos de cada unidade experimental, no inicio, e ao final de cada fase dividindo o peso do grupo pelo número de aves de cada unidade experimental, obtendo-se então o ganho de peso médio por ave. A conversão alimentar (CA) foi calculado utilizando-se os dados referentes ao consumo de ração e o ganho de peso de cada unidade experimental, utilizando a equação $\mathrm{CR} / \mathrm{GP}$

$O$ índice de viabilidade da criação foi calculado pela subtração do percentual de mortalidade obtido em todo período experimental. $\mathrm{O}$ índice de eficiência produtiva (IEP) foi obtido pela fórmula IEP $=(($ ganho de peso $\mathrm{x}$ viabilidade de criação) / (idade das aves em dias x conversão alimentar)) x 100, segundo sugerido por (STRINGHINI et al., 2006).

Ao final dos 42 dias de idade, duas aves de cada unidade experimental, com peso próximo a média da parcela (com no máximo \pm 2 desvios padrões de diferença para média), foram retiradas para a avaliação das características de carcaça (rendimentos de carcaça, peito, coxa e sobre coxa, asas, fígado, coração e moela). As aves foram submetidas a um jejum de 12 horas para o esvaziamento do trato gastrointestinal (CARDOSO et al., 2011) e pesadas individualmente para cálculos do rendimento de carcaça. Para a determinação do rendimento de carcaça, foi considerado o peso da mesma limpa e eviscerada (sem penas, vísceras, cabeça e pés) em relação ao peso vivo após o jejum, obtido antes do abate. Os rendimentos de peito, coxa e sobrecoxa, asa, fígado, coração e moela, foram calculados em relação ao peso da carcaça eviscerada. Para o abate, as aves foram insensibilizadas por meio de eletronarcose seguido de sangria, depenagem, evisceração e retirada dos cortes comerciais e separação de vísceras.

Foi realizada a retirada do intestino de duas aves por unidade experimental para a análise de morfometria intestinal, sendo avaliada a profundidade de cripta, largura da vilosidade e altura da vilosidade. Retirou-se a porção média dos intestinos (cerca de $2 \mathrm{~cm}$ da porção média localizada no jejuno) para as análises. As amostras passaram pelos processos de fixação em formol tamponado $10 \%$ e conservação em álcool $70 \%$. Posteriormente as amostras passaram por processo de desidratação em álcool ascendente e clarificação em xilol.

Em seguida as amostras passaram por processo de confecção dos blocos de parafina e corte dos blocos histológicos, utilizando-se um micrótomo manual (MICROM, International Gmbh 69190, Walldorf, Alemanha). Cortes transversais $(5 \mu \mathrm{m})$ foram obtidos e submetidos ao processo de coloração em hematoxilina/eosina. Para a morfometria, utilizou-se um sistema de análise de imagens, sendo as imagens obtidas através do microscópio Zeiss Axio Imager ${ }^{\circledR}$, com câmera Canon Power Shot $G 9^{\circledR}$ e as imagens obtidas foram analisadas pelo programa AXIOVISION ${ }^{\circledR}$. As medidas de altura das vilosidades foram tomadas a partir da região basal, que coincide com a porção superior das criptas até o ápice do vilo, e as criptas, da base até a região de transição entre a cripta e o vilo. A largura da vilosidade foi mensurada a partir da média de três medidas: na base do vilo, no meio do vilo e no ápice do vilo.

Os dados obtidos foram submetidos a teste de normalidade (Shapiro-Wilk), e posteriormente a análise de variância de uma via (one-way ANOVA). Quando as médias apresentaram diferenças significativas, foram comparadas pelo teste de Tukey. Adotou-se $\alpha=0,05$. Para a realização das análises foi utilizado o pacote estatístico Statistical Analysis System - SAS (1997).

\section{RESULTADOS}

Para o desempenho zootécnico, foram observadas diferenças $(\mathrm{P}<0,05)$ entre os tratamentos, para o ganho de peso aos 21 e aos 42 dias, para o consumo de ração e conversão alimentar aos 42 dias, e no índice de eficiência produtiva. Não foram observadas diferenças $(\mathrm{P}>0,05)$, para o consumo de ração e conversão alimentar aos 21 dias e para a viabilidade. O consumo de ração das aves não foi influenciado pela inclusão de pólen aos 21 dias, porém foi diferente entre os tratamentos aos 42 dias de idade dos animais. A conversão alimentar melhorou com a inclusão do pólen apícola na dieta aos 42 dias de idade, enquanto aos 21 dias de idade não foi verificado efeito do pólen sobre esta variável (Tabela 3 ).

A adição de pólen apícola nas dietas de crescimento (21 a 42 dias de idade) promoveu aumento no ganho de peso nos frangos de corte $(\mathrm{P}<0,05)$ (Tabela 3$)$. Aves que receberam a adição de 15.000 e $30.000 \mathrm{mg} / \mathrm{kg}$ de pólen nas dietas obtiveram um ganho de peso 5,44 e $13,44 \%$ maior, respectivamente, em comparação com as aves não suplementadas do tratamento controle, ao final do período experimental.

O pólen apícola adicionado nas dietas inicial e de crescimento não promoveu diferença $(\mathrm{P}>0,05)$ na viabilidade das aves. Porém aves suplementadas com $30.000 \mathrm{mg} / \mathrm{kg}$ de pólen, não apresentaram mortalidade, enquanto as aves que tiveram dietas com menor inclusão do aditivo ou a sem pólen, apresentaram mortalidades.

A inclusão do pólen apícola influenciou no Índice de Eficiência Produtiva (IEP). Esta resposta foi obtida pelo conjunto de resultados positivos do desempenho zootécnico das aves suplementadas, mostrando que a adição de 30.000 $\mathrm{mg} / \mathrm{kg}$ de pólen apícola promoveu melhor IEP.

O pólen apícola influenciou nas características de carcaça dos frangos de corte, onde foram observadas diferenças $(\mathrm{P}<0,05)$ entre os tratamentos, para os rendimentos de coxa e sobrecoxa, moela, fígado e coração (Tabela 4). No entanto, não foram observadas diferenças $(\mathrm{P}>0,05)$ entre os tratamentos para os rendimentos de carcaça, peito e asas.

A inclusão do pólen apícola promoveu diferenças $(\mathrm{P}<0,05)$ entre os tratamentos para altura do vilo, com maior altura de vilosidade observada no tratamento em que os frangos 
receberam $15.000 \mathrm{mg} / \mathrm{kg}$ de pólen apícola na dieta. A inclusão do pólen apícola não promoveu diferenças $(\mathrm{P}>0,05)$ entre os tratamentos para as variáveis de largura de vilosidade e profundidade de cripta (Tabela 5).

\section{DISCUSSÃO}

Aves suplementadas com o pólen possuem maior desenvolvimento das vilosidades intestinais e glândulas digestivas aumentando desta forma a área de absorção de nutrientes (WANG et al., 2005), e consequentemente promovendo o crescimento e maior desenvolvimento ósseo (KLECZEK et al., 2012), devido ao melhor aproveitamento dos nutrientes.

Acredita-se que o maior desenvolvimento das aves, se deve ao pólen proporcionar benefícios à saúde do organismo e melhorar a microbiota intestinal devido sua ação prébiótica e imunomodulador, o que por sua vez influencia no desempenho dos animais, aumentando significativamente o número de microrganismos benéficos no trato gastrointestinal dos frangos (KROČKO et al., 2012; KAČÁNIOVÁ et al., 2013).

O consumo de ração das aves não foi influenciado pela inclusão de pólen aos 21 dias, porém foi influenciado aos 42 dias de idade dos animais. Entretanto, a inclusão do pólen nas rações das aves, diminuiu o consumo de ração em frangos (HASHMI et al., 2012) e para codornas (CONOGULLARI et al., 2009). Outros produtos apícolas como a própolis não influenciaram o consumo de ração das aves (FRANCO et al., 2007).

A baixa mortalidade observada em frangos suplementados pode ser atribuída ao efeito profilático que o pólen oferece, pois seus compostos e seu efeito prebiótico auxilia a fortalecer o sistema imune do animal com o aumento da velocidade de produção de anticorpos e na resposta imunitária celular (SONG et al., 2005), aumento na atividade fagocitária (ZUO; XU, 2003), aumento da produção de imunoglobulinas (IgM) (OLIVEIRA et al., 2013), por proporcionar um maior desenvolvimento de bactérias benéficas no trato gastrointestinal como os Lactobacillus spp. e Enterococcus spp., impedindo a instalação de cepas patogências (KAČÁNIOVÁ et al., 2013). Além de promover o desenvolvimento precoce do timo e intestino delgado e promoção das respostas imunológicas do baço (WANG et al., 2005; 2007), oferecendo uma maior resistência as aves principalmente nas fases iniciais.

Tabela 3. Desempenho zootécnico de frangos suplementados com níveis crescentes de pólen apícola na dieta.

Table 3. Growth performance of broilers supplemented with increasing levels of pollen in the diet).

\begin{tabular}{lcccc} 
Variáveis & \multicolumn{3}{c}{ Níveis de pólen apícola $(\mathrm{mg} / \mathrm{kg})^{*}$ Valor de $\mathrm{P}^{*}$} \\
\cline { 2 - 4 } & 0 & 15.000 & 30.000 & $<0,01$ \\
Ganho de peso (21 dias) (g) & $637,54 \pm 7,88^{\mathrm{c}}$ & $665,55 \pm 15,82^{\mathrm{b}}$ & $712,60 \pm 7,83^{\mathrm{a}}$ & $\mathrm{NS}$ \\
Consumo de ração (21 dias) (g) & $1207,41 \pm 43,17$ & $1189,52 \pm 88,78$ & $1254,43 \pm 97,58$ & $\mathrm{NS}$ \\
Conversão alimentar (21 dias) & $1,90 \pm 0,12$ & $1,79 \pm 0,06$ & $1,76 \pm 0,06$ & $<0,01$ \\
Ganho de peso (42 dias)(g) & $1914,03 \pm 109,19^{\mathrm{b}}$ & $2024,39 \pm 52,90^{\mathrm{ab}}$ & $2211,25 \pm 181,29^{\mathrm{a}}$ & 0,01 \\
Consumo de ração (42 dias) (g) & $3973,97 \pm 55,43^{\mathrm{b}}$ & $3985,93 \pm 68,55^{\mathrm{b}}$ & $4184,96 \pm 160,81^{\mathrm{a}}$ & 0,03 \\
Conversão alimentar (42 dias) & $2,07 \pm 0,13^{\mathrm{b}}$ & $1,96 \pm 0,07^{\mathrm{ab}}$ & $1,89 \pm 0,06^{\mathrm{a}}$ & $\mathrm{NS}$ \\
Viabilidade (\%) & $88,57 \pm 15,64$ & $97,14 \pm 6,39$ & $100,00 \pm 0,00$ & $<0,01$ \\
Índice de Eficiência Produtiva & $193,92 \pm 29,41^{\mathrm{c}}$ & $238,48 \pm 16,94^{\mathrm{b}}$ & $278,52 \pm 10,35^{\mathrm{a}}$ & \\
\hline
\end{tabular}

*Médias seguidas por letras diferentes na mesma linha diferem entre si pelo teste de Tukey $(\mathrm{P}<0,05)$. NS = Não significativo.

Tabela 4. Características de carcaça de frangos suplementados com níveis crescentes de pólen apícola na dieta. Table 4. Carcass characteristics of broilers supplemented with increasing levels of pollen in the diet).

\begin{tabular}{lcccc} 
Rendimento (\%) & \multicolumn{3}{c}{ Níveis de pólen apícola $(\mathrm{mg} / \mathrm{kg})$} & \multirow{2}{*}{ Valor de $\mathrm{P}^{*}$} \\
\cline { 2 - 4 } & 0 & 15.000 & 30.000 & $\mathrm{NS}$ \\
Carcaça & $69,70 \pm 3,15$ & $71,06 \pm 2,61$ & $72,78 \pm 2,58$ & $\mathrm{NS}$ \\
Peito & $31,18 \pm 1,54$ & $32,64 \pm 1,44$ & $33,36 \pm 2,30$ & 0,01 \\
Coxa e sobrecoxa & $29,87 \pm 1,47^{\mathrm{b}}$ & $31,90 \pm 0,85^{\mathrm{a}}$ & $31,89 \pm 0,74^{\mathrm{a}}$ & $\mathrm{NS}$ \\
Asas & $12,230 \pm 1,06$ & $12,70 \pm 0,21$ & $12,74 \pm 0,51$ & 0,02 \\
Fígado & $2,46 \pm 0,09^{\mathrm{b}}$ & $2,63 \pm 0,11^{\mathrm{a}}$ & $2,48 \pm 0,05^{\mathrm{ab}}$ & $<0,01$ \\
Coração & $0,78 \pm 0,02^{\mathrm{b}}$ & $0,78 \pm 0,01^{\mathrm{b}}$ & $0,87 \pm 0,03^{\mathrm{a}}$ & $<0,01$ \\
Moela & $1,98 \pm 0,03^{\mathrm{b}}$ & $2,08 \pm 0,02^{\mathrm{a}}$ & $2,13 \pm 0,02^{\mathrm{a}}$ & \\
\hline
\end{tabular}

*Médias seguidas por letras diferentes na mesma linha diferem entre si pelo teste de Tukey $(\mathrm{P}<0,05)$. NS = Não significativo.

Tabela 5. Morfometria intestinal de frangos suplementados com níveis crescentes de pólen apícola na dieta.

Table 5. Intestinal morphology of broilers supplemented with increasing levels of pollen in the diet).

\begin{tabular}{lcccc}
\hline Variáveis $(\mu \mathrm{m})$ & \multicolumn{3}{c}{ Níveis de pólen apícola $(\mathrm{mg} / \mathrm{kg})^{*}{\text { Valor de } \mathrm{P}^{*}}^{*}$} \\
\cline { 2 - 4 } & 0 & 15.000 & 30.000 & $\mathrm{NS}$ \\
Profundidade de Cripta & $166,75 \pm 76,16$ & $188,87 \pm 52,85$ & $166,41 \pm 58,10$ & $<0,01$ \\
Altura do vilo & $1483,83 \pm 156,09^{\mathrm{b}}$ & $1716,37 \pm 121,77^{\mathrm{a}}$ & $1567,39 \pm 180,36^{\mathrm{b}}$ & $\mathrm{NS}$ \\
Largura do vilo & $218,41 \pm 43,68$ & $194,30 \pm 43,60$ & $230,50 \pm 80,42$ & \\
\hline
\end{tabular}

*Médias seguidas por letras diferentes na mesma linha diferem entre si pelo teste de Tukey $(\mathrm{P}<0,05)$. NS = Não significativo.

Além de proporcionar maior rendimento, o pólen apícola pode oferecer benefícios à qualidade do produto final. Pois tem efeito positivo sobre a estabilidade oxidativa da carne de frango congelada (HAŠČÍK et al., 2011; 2012), sendo que sua capacidade antioxidante está baseada no bloqueio dos radicais livres e inibição de atividades de peroxidação lipídica
(ABARCA et al., 2004). A adição de pólen proporciona menor percentual de gordura na carcaça (ČUBOŇ et al., 2013), aumento no teor de ácidos graxos essenciais (HAŠČÍK et al., 2014) e efeito positivo sobre parâmetros sensoriais da carne do frango, como sabor, aroma, maciez e suculência (HAŠČ́́K et al., 2013). 
WANG et al. (2007), observaram maior desenvolvimento das vilosidades intestinais nas três primeiras semanas de criação das aves quando suplementadas com pólen. SONG et al. (2005), observaram que as células intestinais foram maiores até as três primeiras semanas de vida dos frangos alimentados com $1,5 \%$ de pólen na dieta, e após esse período não houve diferença significativa. Avaliando a inclusão de própolis em dietas para frangos sobre a morfometria intestinal, BELLONI et al. (2012), afirmam que a propriedade antimicrobiana da própolis (produto apícola), reduz a população de microrganismos patogênicos no lúmen intestinal, o que favorece um maior desenvolvimento das vilosidades e consequentemente uma maior absorção dos alimentos.

Os resultados obtidos na literatura condizem com os resultados observados no atual estudo e mostram que produtos apícolas favorecem o desenvolvimento intestinal de frangos, pelas ações imunoestimulantes e prebióticas que esses alimentos apresentam.

O pólen apícola oferece benefícios ao organismo dos animais de produção e consequente melhora no desempenho zootécnico, contudo, ainda há poucos esclarecimentos de como este aditivo atua no organismo animal e de que maneira ele pode ser utilizado de forma mais eficiente nas dietas dos animais, com isso, mais estudos devem ser realizados para que se esclareça o modo de atuação deste aditivo e para que se possam determinar as melhores doses de inclusão deste alimento em dietas para frangos de corte.

\section{CONCLUSÕES}

Os resultados obtidos neste trabalho indicam que o pólen apícola pode ser utilizado como aditivo alimentar em dietas para frangos de corte pelos benefícios que oferece no desempenho dos animais. Recomenda-se a inclusão de 30.000 $\mathrm{mg} / \mathrm{kg}$ de pólen apícola em dietas para frangos de corte.

\section{REFERÊNCIAS}

ABARCA, N. A.; CAMPOS, M. G.; REYES, A. A.; JIMÉNEz, N. N.; CORRAL, J. H.; VALDEZ, L. S. G. Variability of antioxidant activity among honeybeecollected pollen of different botanical origin. Interciencia, Caracas, v. 29, n. 10, p. 573-5782004.

ABBASS, A. A.; ASELY, A. M.; KANDIEL, M. M. Effects of dietary propolis and pollen on growth performance, fecundity and some hematological parameters of Oreochromis niloticus. Turkish Journal of Fisheries and Aquatic Sciences, v. 12 p. 851-859, 2012. DOI: https://doi.org/10.4194/1303-2712-v12_4_13.

OFFICIAL METHODS OF ANALYSIS OF THE AOAC. AOC 18.ed. Association of Official Analytical Chemists. Gaithersburg, 2005.

ATTIA, Y. A.; HANOUN, A. A.; EL-DIN, A. E. SHEWIKA. Y. E. Effect of bee pollen levels on productive, reproductive and blood traits of NZW rabbits. Journal of Animal Physiology and Animal Nutrition, v. 95, n. 3, p. 294-303, 2010. DOI: https://doi.org/10.1111/j.14390396.2010.01054.x.

BELLONI, M.; ALMEIDA PAZ, I. C.; NÄÄS, I. A.; GARCIA, R. G.; BALDO, G. A.; CAVICHIOLO, F. ALVES, M. C.; CALDARA, F. R. Morfometria intestinal de poedeiras suplementadas com própolis. Agrarian, Dourados, v. 5, n. 16, p.174-180, 2012.

BLIGH, E. G.; DYER, W. J. A rapid method of total lipid extraction and purification. Canadian Journal of
Biochemistry and Physiology, n. 7, v. 8, p. 911-917, 1959. DOI: https://doi.org/10.1139/o59-099

BOGDANOV, S. Quality and standards of pollen and Beeswax. Apiacta, n. 38, p. 334-341, 2004.

CANOGULLARI, S.; BAYLAN, M.; SAHINLER, N.; SAHIN, A. Effects of propolis and pollen supplementations on growth performance and body components of Japanese quails (Coturnix coturnix japonica). Archiv Fur Geflugelkunde, n. 73, p. 173-178, 2009. DOI: https://doi.org/10.1399/eps.2015.86.

CARDOSO, D. M.; MACIEL, M. P.; PASSOS, D. P.; SILVA, F. V., REIS, S. T.; AIURA, F. S. Efeito do uso de complexo enzimático em rações para frangos de corte. Archivos de Zootecnia, v. 60, n. 232, p. 1053-1064, 2011. DOI: http://dx.doi.org/10.4321/S000405922011000400021

CARPES, S. T.; PRADO, A.; MORENO, I. A.; MOURÃO, G. B.; ALENCAR, S. M.; MASSON, M. L. Avaliação do potencial antioxidante do pólen apícola produzido na região sul do Brasil. Química Nova, v. 31, n. 7, p. 16601664, 2008. DOI: http://dx.doi.org/10.1590/S010040422008000700011

CARPES, S. T.; CABRAL, I. S. R.; ROSALEN, P. L.; ALENCAR, S. M.; MASSON, M. L. Caracterização do potencial antimicrobiano dos extratos de pólen apícola da região sul do Brasil. Alimentos e Nutrição, v. 20, n. 2, p. 271-277, 2009

ČUBOŇ, J.; HAŠČÍK, P.; ELIMAM， I.; GARLÍK，J. KAČÁNIOVÁ, M.; MOHAMMED, H. A. The influence of bee pollen on the meat chemical composition for broiler's Ross 308 muscles. Journal of Microbiology. Biotechnology and Food Sciences, v. 2, sp issue on BQRMF, p. 1128-1137, 2013. DOI: https://doi.org/10.11118/actaun201361010071.

DIAS, D. M. B.; OLIVEIRA, M. C.; SILVA, D. M.; BONIFÁCIO, N. P.; CLARO, D. C.; MARCHESIN, W. A. Bee pollen supplementation in diets for rabbit does and growing rabbits. Acta Scientiarum Animal Sciences, Maringá, v. 35, n. 4, p. 425-430, 2013. DOI: http://dx.doi.org/10.4025/actascianimsci.v35i4.18950.

FEÁS, X.; VÁZQUEZ-TATO, M. P.; STEVINHO, L.; SEIJAS, J. A.; IGLESIAS, A. Organic Bee Pollen: Botanical Origin, Nutritional Value, Bioactive Compounds. Antioxidant Activity and Microbiological Quality. Molecules, v. 17, n. 7, p. 8359-8377, 2012. DOI: https://doi.org/10.3390/molecules17078359.

FRANCO, S. S.; ROSA, A. P.; LENGLER, S.; UTTPATEL, R.; ZANELLA, I.; GRESSLER, C.; SOUZA, H. M. Índices produtivos e rendimento de carcaça de frangos de corte alimentados com dietas contendo níveis de extrato etanólico de própolis ou promotores de crescimento convencionais. Ciência Rural, Santa Maria, v. 37, n. 6, p. 1765-1771, 2007. DOI: http://dx.doi.org/10.1590/S010384782007000600041 .

FURTADO, D. A.; AZEVEDO, P. V.; TINÔCO, I. F. F. Análise do conforto térmico em galpões avícolas com diferentes sistemas de acondicionamento. Revista Brasileira de Engenharia Agrícola e Ambiental, Campina Gande, v. 7, n. 3, p. 559-564, 2003.

GEYMAN, J. P. Anaphylactic reaction after ingestion of bee pollen. The Journal of the American Board of Family Practice, v. 7, n. 3, p. 250-252, jun. 1994. 
HAŠČÍK， P.; ELIMAM， I， O.; KAČÁNIOVÁ, M. M.; BOBKO, M.; BENCZOVÁ, E. Oxidative stability of chicken meat after pollen extracts application in their diet. Journal of Microbiology, Biotechnology and Food Sciences, v. 1, n. p. 70-82, jul. 2011.

HAŠČÍK, P.; ELIMAM, I, O.; GARLÍK, J.; KAČÁNIOVÁ, M.; BOBKO, M.; KŇAZOVICKÁ, V.; VAVRIŠINOVÁ, K.; ARPÁŠOVÁ, H.; BUČK, O. Chemical composition of muscle after pollen application in nutrition of broiler chickens. Potravinárstvo, v. 6, n. 2, p. 26-32, fev. 2012 DOI: https://doi.org/10.5219/190

HAŠČÍK, P.; ELIMAM, I, O.; GARLÍK, J.; BOBKO, M.; KROČKO, M. Sensory evaluation of broiler meat after addition slovak bee pollen in their feed mixture. Potravinarstvo, v. 7, n. 1, p. 107-110, jul. 2013. DOI: https://doi.org/10.5219/280.

HAŠČÍK, P.; ELIMAM, I, O.; GARLÍK, J.; KŇAZOVICKÁ, V. Fatty acid content in broiler's ross 308 meat muscles after using bee pollen and probiotic as supplementary diet into their feed mixture. Journal of Microbiology, Biotechnology and Food Sciences, v. 4, n. 1, p. 67-69, ago. 2014.

DOI: https://doi.org/10.15414/jmbfs.2014.4.1.67-69.

HAŠČÍK， P.; TREMBECKÁ， L.; TKÁČOVÁ， J.; KŇAZOVICKÁ, V. Effect of bee pollen dietary supplementation on meat performance of ross 308 broiler chickens. Journal of Microbiology, Biotechnology and Food Sciences, v. 4, n. 3, p. 55-58, fev. 2015. DOI: https://doi.org/10.15414/jmbfs.2015.4.special3.55-58.

HASHMI, M. S.; HASEIK, P.; ELIMAM, I, O.; GARLÍK, J.; BOBKO, M.; MIROSLAVA, K. Effects of bee pollen on the technical and allocative efficiency of meat production of ross 308 broiler. International Journal of Poultry Science, v. 11, n. 11, p. 689-695, nov. 2012. DOI: https://doi.org/10.3923/ijps.2012.689.695.

KAČÁNIOVÁ, M.; ROVNÁ, K.; ARPÁŠOVÁ, H.; HLEBA, L.; PETROVÁ, J.; HAŠČÍK, P.; CUBOŇ, J.; PAVELKOVÁ, A.; CHLEBO, R.; BOBKOVÁ, A.; STRIČIK, M. The effects of bee pollen extracts on the broiler chicken's gastrointestinal micro flora. Research in Veterinary Science, v. 95, n. 1, p. 34-37, 2013. DOI: https://doi.org/10.1016/j.rvsc.2013.02.022.

KLECZEK, K.; MAJEWSKA, K.; MAKOWSKI, W.; MICHALIK, D. The effect of diet supplementation with propolis and bee pollen on the physicochemical properties and strength of tibial bones in broiler chickens. Archiv fur Tierzucht, v. 55, n. 1, p. 97-103. jan. 2012.

KROČKO, M.; ČANIGOVÁ, M.; BEZEKOVÁ, J.; LAVOVÁ, M.; HAŠČÍK, P.; DUCKOVÁ, V. Effect of nutrition with propolis and bee pollen supplements on bacteria colonization pattern in gastrointestinal tract of broiler chickens. Journal of Animal Science and Biotechnology, v. 45, n. 1, p. 63-67, 2012

MORAIS, M.; MOREIRA, L.; FEÁS, X.; ESTEVINHO, L. M. Honeybee-collected pollen from five portuguese natural parks: palynological origin phenolic content antioxidant properties and antimicrobial activity. Food and Chemical Toxicology, v. 49, n. 5, p. 1096-1101, fev. 2011. DOI: https://doi.org/10.1016/j.fct.2011.01.020.

OLIVEIRA, M. C.; SILVA, D. M.; LOCH, F. C. I.; MARTINS, P. C.; DIAS, D. M. B. I.; SIMON, G. A. Effect of Bee Pollen on The Immunity and Tibia Characteristics in Broilers. Brazilian Journal of Poultry Science, v. 15, n. 4, p. 323-328, dez. 2013. DOI: http://dx.doi.org/10.1590/S1516-635X2013000400006.

OPALINSKI, M.; MAIORKA, A.; CUNHA, F.; ROCHA, C.; BORGES, S. A. Adição de complexo enzimático e da granulometria da soja integral desativada melhora desempenho de frangos de corte. Ciência Rural, Santa Maria, v. 40, n. 3, p. 628-632, fev. 2010. DOI: http://dx.doi.org/10.1590/S0103-84782010005000017.

PASCOAL, A.; RODRIGUES, S.; TEIXEIRA, A.; FEÁS, X.; ESTEVINHO, L. M. Biological activities of commercial bee pollens: Antimicrobial, antimutagenic, antioxidant and anti-inflammatory. Food and Chemical Toxicology, v. 63, p. 233-239, 2014. DOI: https://doi.org/10.1016/j.fct.2013.11.010.

PELICANO, E. R. L.; SOUZA, P. A.; SOUZA, H. B. A.; OBA, A.; BOIAGO, M. M.; ZEOLA, N. M. B. L.; SCATOLINI, A. M.; BERTANHA, V. A.; LIMA, T. M. A. Carcass and cut yields and meat qualitative traits of broilers fed diets containing probiotics and prebiotics. Brazilian Journal of Poultry Science, v. 7, n. 3, p. 169175, set. 2005. DOI: http://dx.doi.org/10.1590/S1516$635 \mathrm{X} 2005000300006$.

SAS. Statistical analysis system. User's Guide. $4^{\mathrm{a}}$ ed. North Caroline. 846 pp. 1997.

SONG, Y.; WANG, J.; LI, S.; SHANG, C. Effect of bee pollen on the development of digestive gland of broilers. China Animal Husbandry and Veterinary Medicine, v. 37, p. 14-17, abr. 2005

STRINGHINI, J. H.; ANDRADE, M. L.; ANDRADE, L.; XAVIERII, S. A. G.; CAFÉ, M. B.; LEANDRO, N. S. M. Desempenho, balanço e retenção de nutrientes e biometria dos órgãos digestivos de frangos de corte alimentados com diferentes níveis de proteína na ração pré-inicial. Revista Brasileira de Zootecnia, v. 35, n. 6, p. 2350-2358, dez. 2006. DOI: http://dx.doi.org/10.1590/S151635982006000800022.

WANG, J.; SONG, Y.; WANG, Q. Effect of bee pollen on development of small intestine in broilers. Chinese Journal of Veterinary Science, v. 35, p. 484-488, jun. 2005

WANG, J.; LI, S.; WANG, Q.; XIN, B.; WANG, H. Trophic effect of bee pollen on small intestine in broiler chickens. Journal of Medicinal Food, v. 10, p. 276-280, jul. 2007. DOI: https://doi.org/10.1089/jmf.2006.215

ZAVARIZE，K. C.; SARTORI，J. R.; PELICIA, V. C.; PEZZATO, A. C.; ARAUJO, P. C.; STRADIOTTI, A.C. E.; MADEIRA, L. A.; Glutamina e nucleotídeos na dieta de frangos de corte criados no sistema alternativo. Archivos de Zootecnia, v. 60, n. 232, p. 913-920, dez. 2011. DOI: http://dx.doi.org/10.4321/S000405922011000400008.

ZHANG, K. Y.; YAN, F., C.A.; KEEN, C. A.; WALDROUP, P. W. Evaluation of microencapsulated essential oils and organic acids in diets for broiler chickens. International Journal of Poultry Science, v. 4, n. 9, p. 612-619, 2005. DOI: https://doi.org/10.3923/ijps.2005.612.619.

ZUO, J.; XU, S. Study and application of bee pollen as feed additive. Feed Review, v. 11, n. 1, p. 33-35. 2003 